\title{
A Half-Volume Coil for Efficient Proton Decoupling in Humans at 4 Tesla
}

\author{
Gregor Adriany AND Rolf Gruetter \\ Center for Magnetic Resonance Research, Department of Radiology, Medical School, University of Minnesota, \\ 385 East River Road, Minneapolis, Minnesota 55455
}

Received October 18, 1996; revised December 30, 1996

\begin{abstract}
A quadrature transmit/receive coil for proton-decoupled ${ }^{13} \mathrm{C}$ or ${ }^{31} \mathrm{P}$ spectroscopy half-volume applications, which retains optimal performance on the ${ }^{1} \mathrm{H}$ frequency, was built. Specifically, no RF field profile distortions due to coil interactions were observed. This and the quadrature ${ }^{1} \mathrm{H}$ coil design resulted in a fourfold improvement in the power requirements over conventional, linear-polarized designs. A single lowpass filter of $-0.1 \mathrm{~dB}$ insertion loss was sufficient for broadband proton decoupling experiments on a $4 \mathrm{~T}$ wholebody system. Images and spectra show excellent sensitivity at both frequencies. Broadband decoupling depicting narrow metabolite resonances from glutamate, taurine, and creatine in the human leg and human brain was possible within FDA guidelines for power absorption.
\end{abstract}

Proton decoupling is a necessary requirement to achieve optimal sensitivity for ${ }^{13} \mathrm{C}$ MR spectroscopy (MRS) and may provide substantial improvements for ${ }^{31} \mathrm{P}$ MRS. NOE generation can enhance sensitivity up to threefold for ${ }^{13} \mathrm{C}$ MRS. To a lesser extend, the same holds true for ${ }^{31} \mathrm{P}$ MRS, in that ${ }^{1} \mathrm{H}$ decoupling can increase spectral resolution, especially in the PME and PDE resonances at low magnetic fields (1), and improved signal-to-noise ratio (SNR) can be obtained by NOE generation. These heteronuclear techniques use relatively long and intense RF irradiation at the ${ }^{1} \mathrm{H}$ frequency, which can make it difficult to achieve decoupling in humans within FDA guidelines for power absorption. Both NOE generation and proton decoupling perform well in decoupling RF field amplitude $B_{2}$ above a certain threshold. In order to achieve maximal NOE enhancement and decoupling performance, ${ }^{1} \mathrm{H}$ power is determined by the demand that $B_{2}$ exceed this threshold over the entire sensitive volume of the $\mathrm{X}$-nucleus coil. This requirement can lead to excessive local RF absorption rates when an inhomogenous $\mathrm{RF}$ field is applied. Due to the stronger chemical-shift dispersion of the carbon-bound protons and the larger ${ }^{13} \mathrm{C}-{ }^{1} \mathrm{H}$ coupling, these requirements are by far more stringent for broadband-decoupled ${ }^{13} \mathrm{C}$ MRS than for ${ }^{31} \mathrm{P}$ MRS.

It is clear from these considerations that the coil design is of crucial importance to a successful application of proton decoupling, especially at higher fields such as $4 \mathrm{~T}$.
An ideal coil configuration for in vivo proton-decoupled NMR spectroscopy requires a highly sensitive ${ }^{13} \mathrm{C}$ coil as well as an efficient proton-decoupling coil. Ideally, those coils have very similar areas of sensitivity, yet show no significant electromagnetic interaction or degenerated field patterns. Both aims are especially difficult to achieve for ${ }^{13} \mathrm{C}$ applications, since the quarter wavelength of ${ }^{13} \mathrm{C}$ is very close to the ${ }^{1} \mathrm{H}$ wavelength. In addition, since the power absorption increases with $B_{0}^{2}$, the proton-coil efficiency may determine the feasibility of decoupling within the FDA guidelines $(2-7)$.

Several surface-coil configurations have been used for broadband-decoupled ${ }^{13} \mathrm{C}$ MRS in humans $(4,8-13)$. Many applications successfully used two concentric circular surface coils $(8-10)$. A serious drawback of such a configuration is the inherent ${ }^{1} \mathrm{H}$ flux blockage of the inner ${ }^{13} \mathrm{C}$ coil, since the ${ }^{13} \mathrm{C}$ coil is almost short-circuited at the ${ }^{1} \mathrm{H}$ frequency (9). Consequently the proton-coil performance is rather poor adjacent to the ${ }^{13} \mathrm{C}$ coil, resulting in excessive power requirements for proton decoupling. Despite these drawbacks, concentric coil design was not prohibitive for some clinical applications using small coils at $4.7 \mathrm{~T}(14)$ as well as at 1.5-2.1 $\mathrm{T}(15,16)$. However, for the volumes needed for human applications at $4 \mathrm{~T}$, we found that the performance of the proton coil in a double concentric arrangement was not sufficient for decoupling within FDA guidelines.

Alternatively, double-tuned surface coils (17-20) have the advantage that the sensitivity profile is the same at both frequencies and that the problem of flux blockage is eliminated. However, in terms of a decoupling application it is very difficult to design circuitry that provides sufficient electromagnetic isolation without limiting the coil performance for one of the nuclei. This is especially true for double-tuned coils at very high fields, such as $4 \mathrm{~T}$, since a very-high-field coil requires distributed capacitors to compensate for coilcurrent phase errors that become severe if coil dimensions approach the quarter wavelength.

To avoid substantial coil-flux coupling, the coils or the coil fields can be arranged in an orthogonal fashion $(4,12,13)$. Bottomley et al. (4) used a figure-8 type geome- 
try ("butterfly design") (21) for the ${ }^{1} \mathrm{H}$ decoupling coil at $1.5 \mathrm{~T}$, where the proton $B_{2}$ field is parallel to the ${ }^{13} \mathrm{C}$ coil plane. Merkle et al. (12) described a similar design at $4 \mathrm{~T}$ with the ${ }^{1} \mathrm{H}$ coil loops of the figure- 8 coil connected in parallel and the overall coil length kept as short as possible. Since the physical coil length approaches the ${ }^{1} \mathrm{H}$ wavelength at $4 \mathrm{~T}$, a figure- 8 coil connected in parallel is preferable over serial-connected designs. Inherent in all figure- 8 type coil designs is the rapidly decreasing $B_{2}$ along the ${ }^{13} \mathrm{C}$ coil axis, which may require excessive ${ }^{1} \mathrm{H}$ power to decouple the entire volume of the ${ }^{13} \mathrm{C}$ coil and thus may lead to excessive local SAR values close to the crossing point of the coil loops.

All of the aforementioned designs were linearly polarized coils. However, since the decoupling power needed increases with $B_{0}^{2}$, it is highly desirable to use the benefits of a quadrature ${ }^{1} \mathrm{H}$ coil, which can reduce the power requirements up to two-fold (22). We have previously shown the principles of utilizing surface coils to generate circularly polarized RF fields for decoupling and imaging (13). We therefore sought a combination of basic transmit/receive coils, where a linearly polarized ${ }^{13} \mathrm{C}$ coil minimally affects the $B_{2}$ field distribution of a quadrature ${ }^{1} \mathrm{H}$ coil which permits efficient lowpower decoupling at $4 \mathrm{~T}$ with negligible performance loss on either channel.

The coil was mounted on a half-cylindrical acrylic glass former held in place by a wooden support structure. The curvature of the acrylic glass former was chosen to fit an average human head comfortably. The two circular ${ }^{1} \mathrm{H}$ coil loops were arranged spatially on the acrylic glass support structure to generate a quadrature field $(23-25)$ in the area adjacent to the ${ }^{13} \mathrm{C}$ coil (Fig. 1b). The ${ }^{13} \mathrm{C}$ coil consisted of a single-loop solenoidal coil with a diameter of $7 \mathrm{~cm}$. This coil was made from $\frac{1}{4}$ " copper tubing and did not have any capacitive shortenings. Coarse tuning to $42.5 \mathrm{MHz}$ was

a

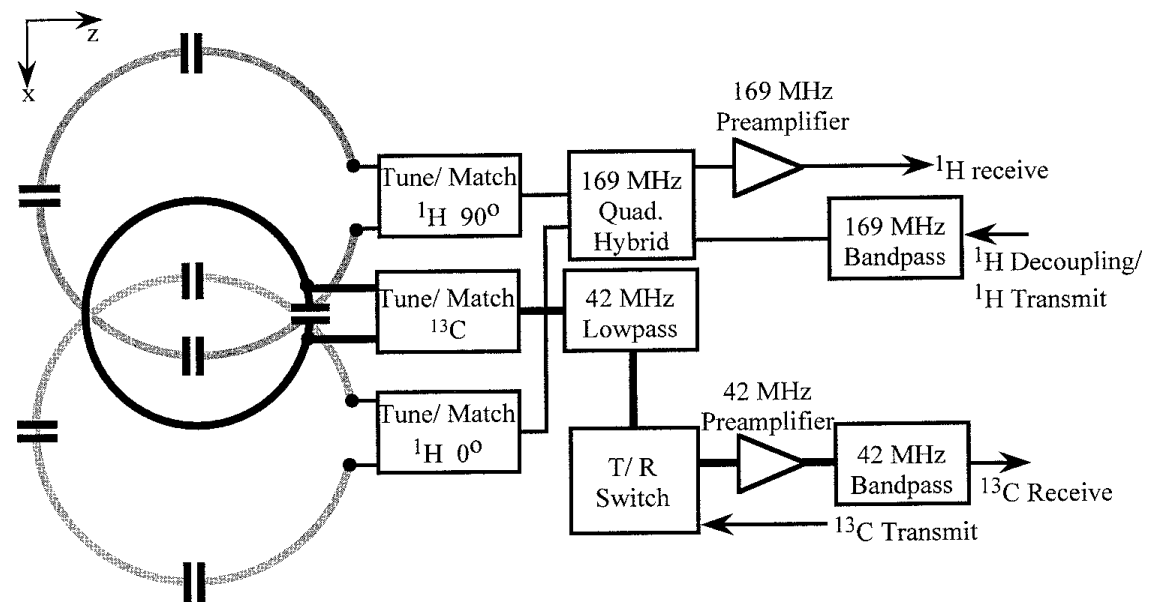

b

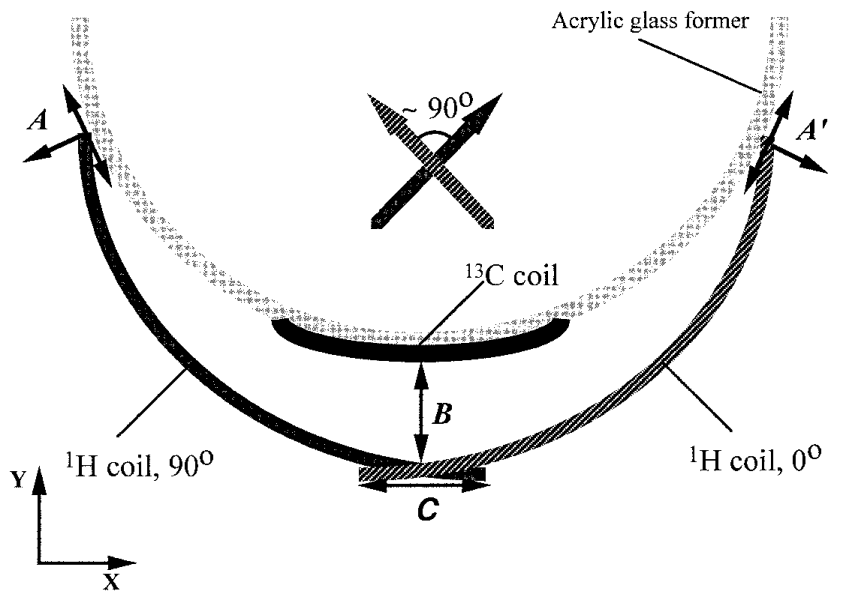

FIG. 1. (a) Schematic of the overall coil arrangement including the filters, preamplifiers, and T/R switch. (b) Schematic of the coil in the axial plane. The arrows indicate the different directions along which the proton decoupling coil (shaded) was spatially varied to minimize mutual coil coupling and to optimize the quadrature field. Change of $A, A^{\prime}$, and $B$ resulted in minimized interaction between the ${ }^{1} \mathrm{H}$ coil and the ${ }^{13} \mathrm{C}$ coil (black). The ${ }^{1} \mathrm{H}$ coils were geometrically decoupled through adjustments of the overlap $C$. The overlap $C$ is determined by the ${ }^{1} \mathrm{H}$ coil diameter and to a lesser extent by the overall spatial arrangement; therefore a change along $A, A^{\prime}$, and $B$ leads to a readjustment of $C$. 
TABLE 1

Measurements of the Mutual Coil Coupling and the Coil Quality Factor $Q$

\begin{tabular}{lccccccc}
\hline & \multicolumn{3}{c}{ Coil coupling $\left(S_{12}\right)$, loaded $^{a}$} & & \multicolumn{2}{c}{$Q_{\mathrm{o}} / Q_{\text {load }}$} \\
\cline { 2 - 6 } & ${ }^{13} \mathrm{C}$ coil & $\begin{array}{c}{ }^{1} \mathrm{H} \text { coil } \\
\left(0^{\circ}\right)^{b}\end{array}$ & $\begin{array}{c}{ }^{1} \mathrm{H} \text { coil } \\
\left(90^{\circ}\right)^{b}\end{array}$ & & $\begin{array}{c}{ }^{13} \mathrm{C} \text { coil } \\
\text { only }^{c}\end{array}$ & $\begin{array}{c}{ }^{1} \mathrm{H} \text { coil } \\
\text { only }^{c}\end{array}$ & $\begin{array}{c}\text { All coils } \\
\text { present }^{d}\end{array}$ \\
\hline${ }^{13} \mathrm{C}$ coil & - & $-20.4 \mathrm{~dB}$ & $-21.5 \mathrm{~dB}$ & & $550 / 78$ & - & $450 / 78$ \\
${ }^{1} \mathrm{H}$ coil $\left(0^{\circ}\right)^{b}$ & $-20.4 \mathrm{~dB}$ & - & $-26.3 \mathrm{~dB}$ & - & $330 / 50$ & $290 / 50$ \\
${ }^{1} \mathrm{H}$ coil $\left(90^{\circ}\right)^{b}$ & $-21.5 \mathrm{~dB}$ & $-26.3 \mathrm{~dB}$ & - & - & $335 / 50$ & $290 / 50$ \\
\hline
\end{tabular}

${ }^{a}$ Phantom, 2.51 of $100 \mathrm{mM} \mathrm{NaCl}$ solution.

${ }^{b}$ See Fig. 1b.

${ }^{c}$ Only the indicated coil; all other coil loops were physically removed.

${ }^{d}$ Complete coil configuration.

achieved with a $100 \mathrm{pF}$ high-Q ceramic capacitor (American Technical Ceramics, Huntington Station, New York). To utilize the high surface coil sensitivity close to the ${ }^{13} \mathrm{C}$ coil plane, we reduced the distance to the sample to less than 1 $\mathrm{cm}$ by cutting a groove into the acrylic glass former for the ${ }^{13} \mathrm{C}$ coil wire. Each of the ${ }^{1} \mathrm{H}$ coil loops was $12 \mathrm{~cm}$ in diameter and was three times capacitively shortened using high$Q 15 \mathrm{pF}$ ceramic capacitors (American Technical Ceramics). The ${ }^{1} \mathrm{H}$ coil loops were constructed from $\frac{3}{8}{ }^{\prime \prime}$ copper tubing. The loop diameter of $12 \mathrm{~cm}$ for the ${ }^{1} \mathrm{H}$ coil was chosen to optimize the quadrature field in the sensitive volume of the ${ }^{13} \mathrm{C}$ coil and to minimize the coupling between the quadrature ${ }^{1} \mathrm{H}$ coil and the ${ }^{13} \mathrm{C}$ coil. To reduce high flux regions close to the wires, we maintained a minimum distance of at least $1.5 \mathrm{~cm}$ between the ${ }^{1} \mathrm{H}$ coil wires and the observed tissue. As indicated in the cross-sectional diagram in Fig. 1b, inherent in the design is an increased distance of approximately $3 \mathrm{~cm}$ between the tissue and the very-highflux area close to the wire overlap area between the two proton coils. The coils were tuned and matched to $50 \Omega$ and decoupled from each other while loaded on the laboratory bench with a suitable phantom (2.5 1 destilled water, 100 $\mathrm{ml}$ saline) as well as a human leg. Electromagnetic coupling between the coils was minimized by altering the overlap between the ${ }^{1} \mathrm{H}$ coil loops as assessed using a HP 4396A network analyzer (Hewlett Packard, Palo Alto, California). Additional reduction was achieved by spatially rearranging the quadrature ${ }^{1} \mathrm{H}$ coil toward the fixed mounted ${ }^{13} \mathrm{C}$ coil (Fig. 1b). We optimized the coil decoupling in a standard $\mathrm{S}_{12}$ analyzer measurement, transmitting into the ${ }^{13} \mathrm{C}$ coil and receiving with one of the ${ }^{1} \mathrm{H}$ coil loops and vice versa. As summarized in Table 1, the resulting coupling between the ${ }^{13} \mathrm{C}$ coil and either of the ${ }^{1} \mathrm{H}$ coil loops was less than $-20 \mathrm{~dB}$ for various loading situations (phantom, human leg, human head). We found the achieved isolation to be sufficient for broadband decoupling without addition of further performance-limiting circuit elements such as $\lambda / 4$ lines. The balanced output circuits (26) to tune and match each of the coils were shielded to reduce surface wave effects due to coil asymmetries, and optimal ${ }^{13} \mathrm{C}$ coil performance was maintained by arranging the shielding boxes at least $5 \mathrm{~cm}$ away from the ${ }^{13} \mathrm{C}$ coil wire. For the balanced output circuits we used variable high- $Q$, high voltage capacitors (Voltronics, Denville, New Jersey).

Experiments were performed on a $4 \mathrm{~T}$ whole-body Siemens (Siemens Medical Systems, Erlangen, Germany) magnet interfaced with a Sisco/Varian (Palo Alto, California) console. For heteronuclear experiments, we used a custom-designed 169 $\mathrm{MHz}$ bandpass filter (FSY Microwave Inc., Rockville, Maryland) with an insertion loss of $-1.5 \mathrm{~dB}$ and with $-80 \mathrm{~dB}$ stopband attenuation in the proton decouple path (Fig. 1a). A single lowpass filter (FSY Microwave Inc.) with $-0.1 \mathrm{~dB}$ insertion loss at $42.5 \mathrm{MHz}$ and $-80 \mathrm{~dB}$ stopband attenuation at 169 $\mathrm{MHz}$ was inserted between the ${ }^{13} \mathrm{C}$ coil and the T/R switch. A homebuilt narrowband preamplifier with a low noise figure of $0.3 \mathrm{~dB}$ and with $+34 \mathrm{~dB}$ gain at $42.5 \mathrm{MHz}$ amplified the ${ }^{13} \mathrm{C}$ signal immediately after the $T / R$ switch. The ${ }^{1} \mathrm{H}$ coil loops were connected through a quadrature hybrid to the transmit port and to the $169 \mathrm{MHz}$ preamplifier. We calibrated the ${ }^{1} \mathrm{H}$ decoupler power at the input transmit port of the quadrature hybrid (KDI Electronics, Whippany, New Jersey). For the calibration measurement, we used a $-30 \mathrm{~dB}$ high-power attenuator and measured with a power meter (Rhode \& Schwartz, Munich, Germany) during long decoupler-pulse trains. We verified the reading by measuring the peak-to-peak voltage with an oscilloscope, taking the attenuation of the measurement lines into account.

To determine residual field interactions, we measured the difference in the ${ }^{13} \mathrm{C}$ coil quality factor $Q$ with the tuned quadrature ${ }^{1} \mathrm{H}$ coil in place and after physically removing the ${ }^{1} \mathrm{H}$ coil loops (Table 1 ). There was no measurable difference in the loaded case, which indicated negligible coil interaction or field distortion. The loaded quality factor $\left(Q_{\mathrm{L}}\right)$ for the ${ }^{13} \mathrm{C}$ coil was unchanged at $Q_{\mathrm{L}}=78$. We verified this by assessing the ${ }^{13} \mathrm{C}$ coil performance with and without the quadrature ${ }^{1} \mathrm{H}$ coil by measuring the ${ }^{13} \mathrm{C}$ coil pulse widths 
on a small sphere containing ${ }^{13} \mathrm{C}$ formic acid placed at the ${ }^{13} \mathrm{C}$ coil center, which were unaffected by the quadrature ${ }^{1} \mathrm{H}$ coil. In contrast to a standard double concentric coil consisting of a $7 \mathrm{~cm}{ }^{13} \mathrm{C}$ coil and a linearly polarized $14 \mathrm{~cm}{ }^{1} \mathrm{H}$ coil, we found that the presented coil showed no significant degradation of the ${ }^{1} \mathrm{H}$ RF field distribution by the ${ }^{13} \mathrm{C}$ coil. The ${ }^{1} \mathrm{H} 90^{\circ}$ pulse width at the ${ }^{13} \mathrm{C}$ coil center was $500 \mu \mathrm{s}$ at $30 \mathrm{~W}$ peak power for the quadrature proton coil compared to $120 \mathrm{~W}$ peak power for the linear proton coil with a double concentric arrangement. This fourfold improvement in the power requirements can be explained by the quadrature gain, by the reduced coil size of either of the ${ }^{1} \mathrm{H}$ loops, and by the greatly reduced flux interactions. Assuming the duty cycle (DC) of the proton decoupling to be $10 \%$, the decoupling peak power of $30 \mathrm{~W}\left(P_{\max }\right)$ leads to $3 \mathrm{~W}$ average RF radiation $\left(P_{\text {aver. }}\right)$. Furthermore, with a coil efficiency of approximately $83 \%$ due to the achieved $Q_{0} / Q_{1}$ ratio of 5.8 (Table $1)$ and neglecting radiation losses, one can assume that approximately $2.5 \mathrm{~W}$ is maximally irradiated into the load $\left(P_{\text {load }}\right)$, since

$$
P_{\text {load }}=P_{\text {max }} \times \mathrm{DC} \times\left(1-Q_{1} / Q_{0}\right) \approx 2.5 \mathrm{~W} .
$$
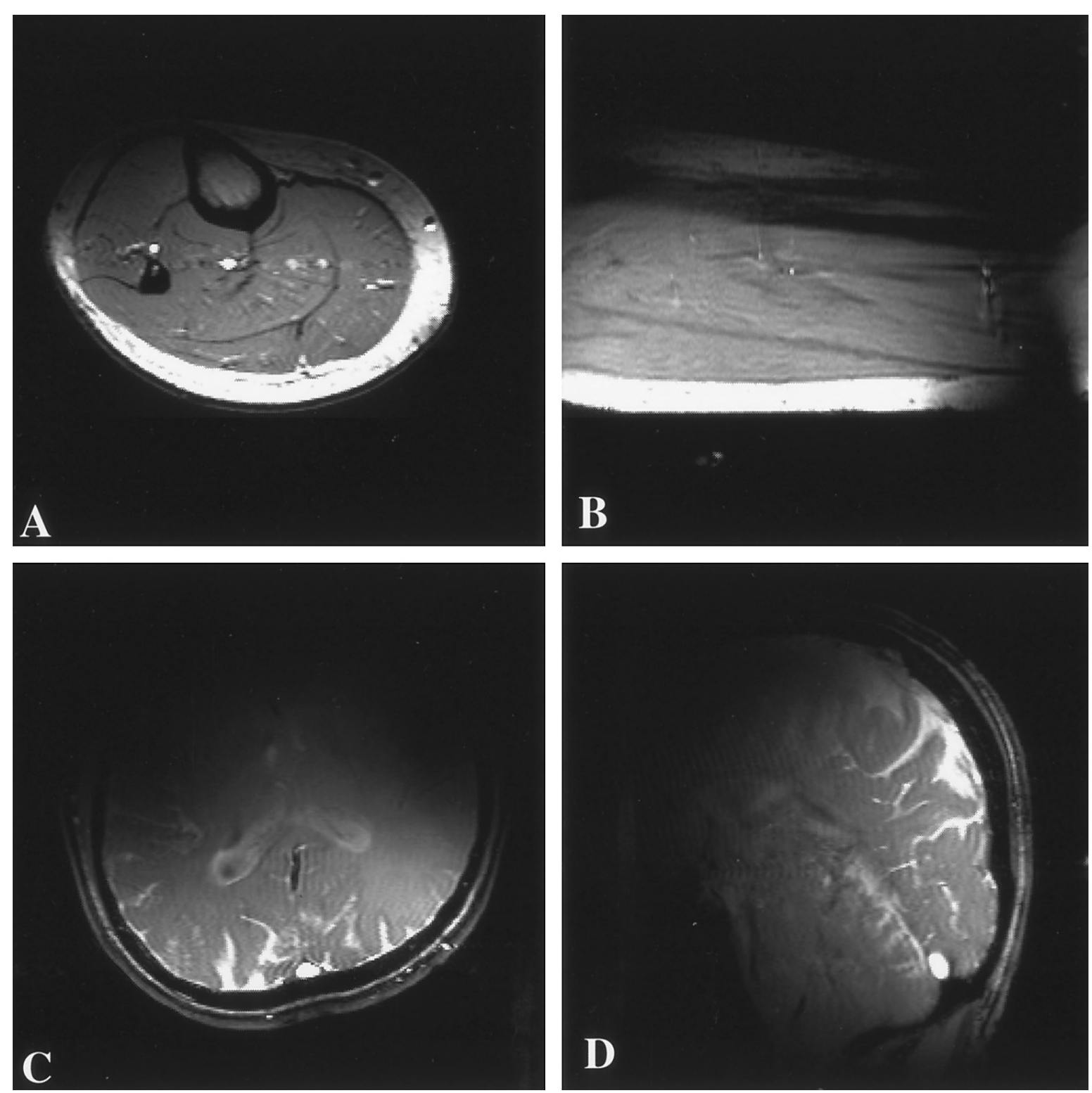

FIG. 2. FLASH (27) images of a human leg and head (FOV $20 \times 20 \mathrm{~cm}$, TR $=60 \mathrm{~ms}$, TE $=7 \mathrm{~ms}$, flip angle $\left.30^{\circ}\right)$ : $(\mathrm{A})$ axial image of a human leg, (B) sagittal image of a human leg, (C) axial image of a human head, (D) sagittal image of a human head. The image intensity is approximately proportional to $B_{2}^{2}$, due to the $30^{\circ}$ flip angle; therefore the images display the overall power distribution. There are no apparent "hot spots" or dielectric resonances. Note the small sphere containing ${ }^{13} \mathrm{C}$ formic acid in the sagittal images (B, D), indicating the ${ }^{13} \mathrm{C}$ coil plane. 


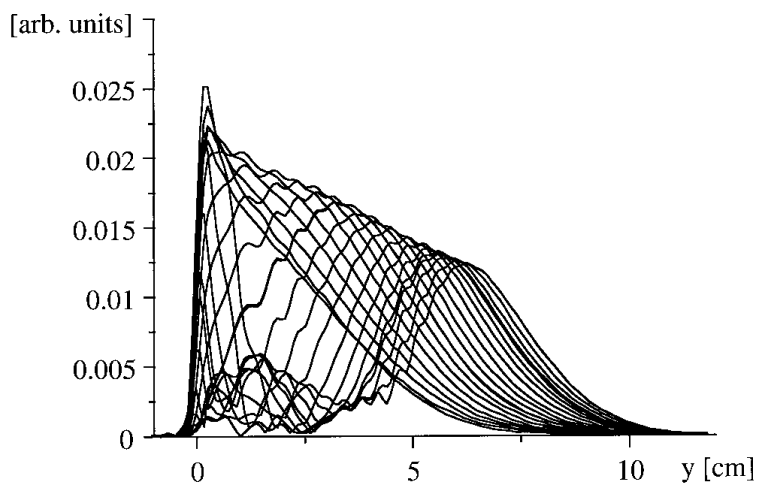

FIG. 3. Sensitivity profiles of the ${ }^{1} \mathrm{H}$ quadrature coil along the ${ }^{13} \mathrm{C}$ coil axis. The data were obtained from a selected column by using FASTMAP (28) while increasing the RF power. The envelope of the projections therefore maps the ${ }^{1} \mathrm{H}$ coil $B_{2}$ profile. The highest ${ }^{1} \mathrm{H}$ coil $B_{2}$ sensitivity was close to the ${ }^{13} \mathrm{C}$ coil plane. An aqueous solution of $250 \mathrm{mM}$ glucose (100 $\mathrm{m} M \mathrm{NaCl}$ ) was used. The edge artifact observed in phantom studies ( 5 $\mathrm{mm}$ rim of high intensity) was caused by dielectric resonances due to the phantom geometry and was not observed in vivo.

As can be seen from imaging experiments (Fig. 2), excellent homogeneity was present in at least a $16 \times 12 \times 8 \mathrm{~cm}$ volume adjacent to the ${ }^{13} \mathrm{C}$ coil; therefore, most of this power will be absorbed by approximately $1.5 \mathrm{~kg}$ body tissue (31). This is well below FDA guidelines for power absorption. It should be emphasized that excellent RF homogeneity, especially the absence of "hot spots" at the sample surface, implies low local SAR values. However, broadband decoupling can potentially irradiate a critical level of RF power locally into the sample. As pointed out by Bottomley et al. $(4,5)$, local SAR limits can be exceeded when using an inhomogeneous coil for proton decoupling. A figure- 8 type ${ }^{1} \mathrm{H}$ decoupling coil $(4,5,12,13)$ is specifically critical in that regard mainly for two reasons: First, the crossing point of the two loops leads to a noticeable hot spot at the ${ }^{13} \mathrm{C}$ coil center. Second, the decrease in sensitivity with depth is relatively rapid, resulting in an inhomogeneous coil profile along the $y$ axis. Therefore, a substantial amount of RF power is deposited in the tissue close to the central crossing point of the figure- 8 type ${ }^{1} \mathrm{H}$ coil. Removing this crossing area away from the tissue, on the other hand, leads to a far less efficient coil and ultimately results in even higher power requirements.

We found that the half-volume quadrature ${ }^{1} \mathrm{H}$ decoupled coil design presented is less critical in terms of excessive local SAR than all of the aforementioned coil designs for three reasons: First, the quadrature coil has far reduced power requirements and is more efficient. Second, to achieve an optimal quadrature field in the ${ }^{13} \mathrm{C}$ coil center, the two ${ }^{1} \mathrm{H}$ coil loops were placed as perpendicular as possible, which increased the distance between the wires in the very sensitive wire overlap area and the tissue, and therefore the spatial distribution of the deposited power was more homogeneous. Third, the quadrature ${ }^{1} \mathrm{H}$ coil has a very modest decrease in sensitivity along the $y$ axis, which is linear, as shown in Fig. 3.

In a worst-case calculation, to estimate the local SAR, we measured the $B_{2}$ profile along the vertical ${ }^{13} \mathrm{C}$ coil axis in a phantom (Fig. 3). We measured an approximately linear decrease to $45 \%$ of the maximal sensitivity at a depth of 8 $\mathrm{cm}$. Profiles obtained in imaging experiments on the human leg and head were found to decrease similarly with depth ( $y$ axis); however, the edge effect due to dielectric resonances as measured in the phantom (Fig. 3) was not observed in in vivo MRI projections as well as in in vivo decoupler power calibrations and hence was ignored. Based on Faraday's law we assumed the local SAR is proportional to $B_{2}^{2}$ using Eq. [2] for $B_{2}^{2}$ :

$$
B_{2}(y)^{2}=\left(B_{2 \max }-\left(0.07 \times B_{2 \max } \times y[\mathrm{~cm}]\right)\right)^{2}
$$
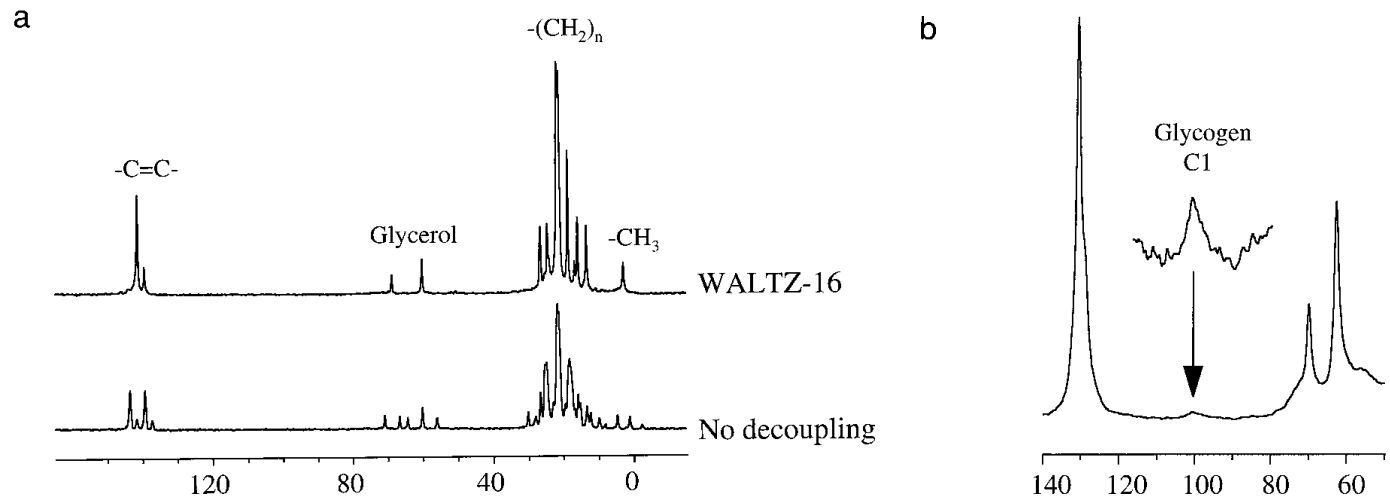

FIG. 4. (a) Shows a ${ }^{13} \mathrm{C}$ NMR spectrum of the human calf muscle acquired in $16 \mathrm{~s}$ without (bottom) and with (top) WALTZ-16 (29) broadband decoupling ( TR $=1.1 \mathrm{~s}, 10 \% \mathrm{DC}$ ). The decoupled spectrum (top) shows that all ${ }^{1} \mathrm{H}$-based ${ }^{13} \mathrm{C}$ resonances from the methyl peak at 9 ppm to the olefinic carbons at $130 \mathrm{ppm}$ are decoupled. (b) The expansion of a ${ }^{13} \mathrm{C}$ NMR spectrum shows detection of the calf muscle glycogen resonances from a female subject at $100.5 \mathrm{ppm}$ in $32 \mathrm{~s}$ ( TR $=126 \mathrm{~ms}, 256$ scans, $120^{\circ}$ hard pulse at the coil center, $26 \mathrm{~ms}$ WALTZ-16 (13 W) of $500 \mathrm{~Hz}$ bandwidth). The average dissipated RF power was less than $2.5 \mathrm{~W}$. 


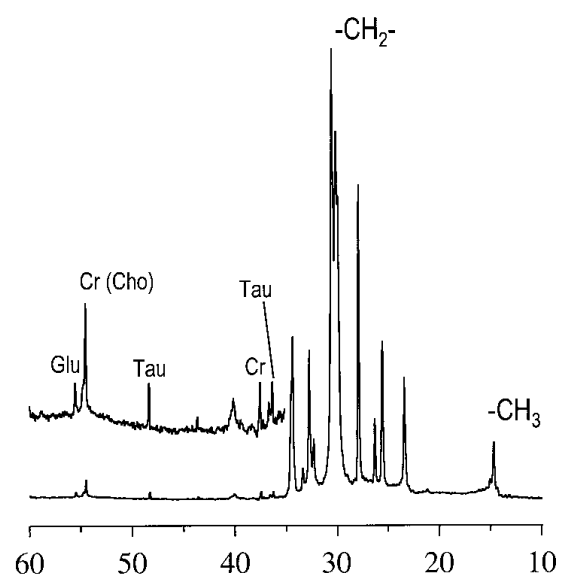

b

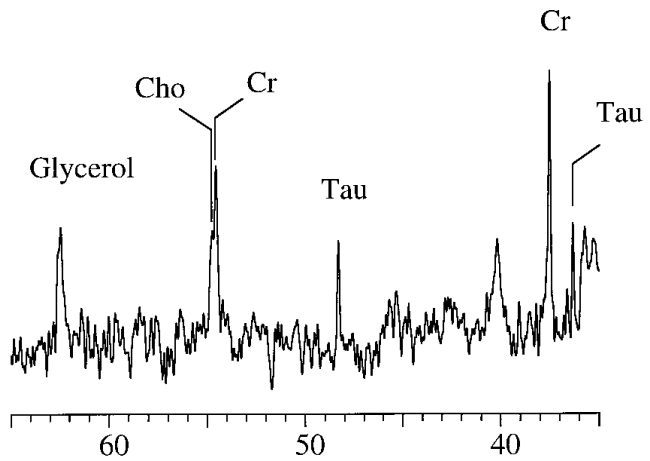

C

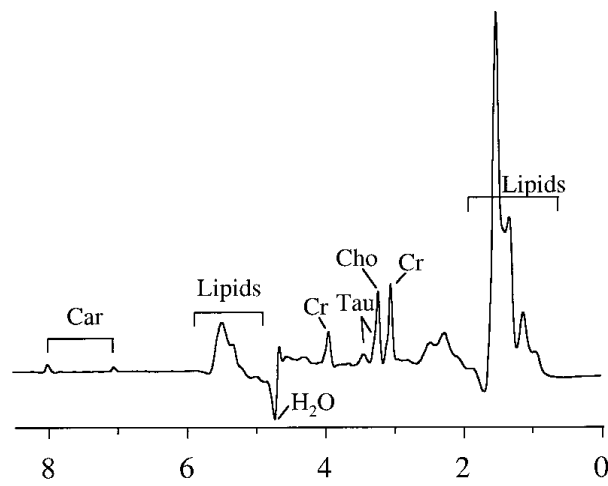

FIG. 5. (a) Expansion of an unlocalized ${ }^{13} \mathrm{C}$ MR spectrum acquired from a human calf muscle using an adiabatic BIR-4 pulse ( 30 ) with NOE generation and WALTZ-16 (Acq.time $=170 \mathrm{~ms}, \mathrm{TR}=3 \mathrm{~s}$ ), showing narrow resonances from the C2 of glutamate $(\mathrm{Glu})(55.6 \mathrm{ppm})$, creatine $(\mathrm{CR})$ methylene + choline (Cho) methyl $(54.8 \mathrm{ppm})$, taurine (Tau) (48.6 and $35.3 \mathrm{ppm})$, and creatine methyl at $37.5 \mathrm{ppm}$ and high spectral detail in the lipid resonances. (b) The effect of three-dimensional localization using ${ }^{1} \mathrm{H}$-based localization combined with polarization transfer (PRECISELY (31)) shows that Tau can be readily observed in a male triceps surae muscle spectrum (ISIS, TR = $3 \mathrm{~s}$, WALTZ-16, Acq.time $=171 \mathrm{~ms}$, $72 \mathrm{ml}$ ). (c) Concomitant localized ${ }^{1} \mathrm{H}$ MR spectra of the human calf muscle (male, triceps surae) at $4 \mathrm{~T}$ acquired using $\mathrm{STEAM}(\mathrm{TR}=3 \mathrm{~s}$, TE $=26 \mathrm{~ms}$, TM $=$ $10 \mathrm{~ms}$, measurement time $3 \mathrm{~min}, 72 \mathrm{ml}$ ) as described previously (32).

Neglecting RF power deposition deeper than $8 \mathrm{~cm}$, we calculated by integrating Eq. [2] that at most $21 \%$ of the total irradiated power $\left(P_{\text {load }}\right)$ is deposited within the first centimeter of tissue. At least $160 \mathrm{ml}$ of tissue are within this first centimeter of tissue, as judged from MRI data (Fig. 2), which leads to $160 \mathrm{~g}$ of tissue, assuming a specific gravity of 1 for the tissue (muscle, brain tissue). Therefore, the highest local SAR $\left(\mathrm{SAR}_{\mathrm{Local}}\right)$ for a $10 \%$ duty cycle resulting in $P_{\text {load }} \approx 2.5 \mathrm{~W}$ (Eq. [1]) can be estimated not to exceed

$$
\mathrm{SAR}_{\text {local }}<P_{\text {load }} \times 0.21 / 0.160 \mathrm{~kg}=3.3 \mathrm{~W} / \mathrm{kg} .
$$

Note that these assumptions overestimate the local SAR encountered in vivo, since much of the first centimeter will contain subcutaneous fat tissue with a fourfold decreased conductivity compared to muscle or brain tissue. The calculated maximal $\mathrm{SAR}_{\text {local }}$ (Eq. [3]) is within the FDA guidelines for local power deposition.

The ${ }^{1} \mathrm{H}$ coil homogeneity was sufficient for ${ }^{1} \mathrm{H}$ MRI of the entire cross section of the human calf muscle (Figs. 2A and $2 \mathrm{~B}$ ) and the posterior two-thirds of the human brain (Figs. 2C and 2D). Figure 3 shows that the $B_{2}$ profile along the ${ }^{13} \mathrm{C}$ coil axis is very homogeneous over the entire ${ }^{13} \mathrm{C}$ coil. We used the excellent sensitivity provided by this coil to acquire spectra from low-concentration metabolites in the human calf muscle. The spectra of the human calf muscle shown in Fig. 4a were acquired in $16 \mathrm{~s}$ without (bottom) and with (top) broadband decoupling using WALTZ-16 (29). The decoupled spectrum (top) shows that all ${ }^{13} \mathrm{C}$ resonances from the methyl peak at $9 \mathrm{ppm}$ to the olefinic carbons at $130 \mathrm{ppm}$ were decoupled, which demonstrates that effective broadband decoupling can be easily achieved at $4 \mathrm{~T}$ using the present coil design. The high sensitivity of the ${ }^{13} \mathrm{C}$ coil is illustrated in Fig. 4b, where muscle glycogen was detected in a human calf muscle in $32 \mathrm{~s}$ with a SNR of 20:1, which compares favorably with the 21:1 SNR reported for 5 min measurements at $4.7 \mathrm{~T}$ using a $3.5 \mathrm{~cm}{ }^{13} \mathrm{C}$ coil $(15)$. The unlocalized ${ }^{13} \mathrm{C}$ spectrum in Fig. 5a shows resonances 
from C2 of glutamate (Glu) (55.6 ppm), creatine $(\mathrm{Cr})+$ choline (Cho) (54.8 ppm), taurine (Tau) (48.6 and 36.3 ppm), and $\mathrm{Cr}$ (37.5 ppm). Note the excellent spectral resolution in the lipid methylene peak area at $30 \mathrm{ppm}$. Figure $5 \mathrm{~b}$ shows 3D localization using PRECISELY (31); Tau can be readily observed. The observed intensity of Tau relative to the $30 \mathrm{~m} M \mathrm{Cr}$ peak suggests that the Tau concentration is approximately $10 \mathrm{~m} M$. An example of concomitant proton spectroscopy is shown in Fig. 5c, acquired using STEAM as described previously (32). Peaks from the carnosine histidine resonances, $\mathrm{Cr}$, Tau, and lipids are observed. The Tau peak area was found to agree with the relative intensity observed in the ${ }^{13} \mathrm{C}$ spectrum.

Proton images and ${ }^{13} \mathrm{C}$ spectra demonstrated the feasibility of proton decoupling for in vivo experiments on the human leg muscle and in the posterior half of the human brain at $4 \mathrm{~T}$ within power-absorption guidelines. Since the presented coil assembly consists of a combination of well-established, solenoidal transmit/receive coils, the coil is straightforward to build. This coil design can also be extended easily to lower frequencies and/or to ${ }^{31} \mathrm{P}$ NMR.

\section{ACKNOWLEDGMENTS}

We thank Dr. Hellmut Merkle for discussions using his expertise in highfrequency coil design. The authors are particularly grateful for Professor Kamil Ugurbil's support and encouragement. This work was partly funded by NIH Grant RR08079.

\section{REFERENCES}

1. P. R. Luyten, G. Bruntink, F. M. Sloof, J . I. Vermeulen, J . I. van der Heijden, J. A. den Hollander, and A. Heerschap, NMR Biomed. 1, 177 (1989).

2. C-N. Chen, V. J. Sank, and D. I. Hoult, Magn. Reson. Med. 3, 722 (1986).

3. P. Roeschmann, Med. Phys. 14, 922 (1987).

4. P. A. Bottomley, C.J. Hardy, P. B. Roemer, and O. M. Mueller, Magn. Reson. Med. 12, 348 (1989).

5. P. A. Bottomley and P. B. Roemer, Ann. N.Y. Acad. Sci. 649, 144 (1992).

6. H. Barfuss, H. Fischer, D. Hentschel, R. Ladebeck, A. Oppelt, R. Wittig, W. Duerr, and R. Oppelt, NMR Biomed. 3, 31 (1990).

7. J. R. Keltner, J. W. Carlson, M. S. Ross, S. T. S. Wong, T. L. Wong, and T. F. Budinger, Magn. Reson. Med. 22, 467 (1991).

8. N. V. Reo, C. S. Ewy, B. A. Siegfried, and J.J.H. Ackerman, J. Magn. Reson. 58, 76 (1984).
9. B. Tiffon, J. Mispelter, and J . M. Lhoste, J. Magn. Reson. 68, 544 (1986).

10. J . Mispelter, B. Tiffon, E. Quiniou, and J. M. Lhoste, J . Magn. Reson. 82, 622 (1989).

11. J. Tropp, K. Lim, N. Sailasuta, T. Raidy, D. J. Schaefer, and R. Hurd, Abstracts of the International Society of Magnetic Resonance in Medicine, New York, p. 1237, April 27-May 3, 1996.

12. H. Merkle, H. Wei, M. Garwood, and K. Ugurbil, J. Magn. Reson. 99, 480 (1992).

13. H. Merkle, R. Gruetter, G. Adriany, and K. Ugurbil, Abstracts of the Society of Magnetic Resonance, Nice, France, p. 962, August 1925, 1995.

14. T. B. Price, D. L. Rothman, M. J. Avison, P. Buonamico, and R. G. Shulman, J. Appl. Physiol. 70, 1836 (1991).

15. N. Beckmann, J. Seelig, and H. Wick, Magn. Reson. Med. 16, 150 (1990).

16. R. Gruetter, D. L. Rothman, E. J. Novotny, and R. G. Shulman, Magn. Reson. Med. 25, 204 (1992).

17. J. A. den Hollander, K. L. Behar, and R. G. Shulman, J. Magn. Reson. 57, 311 (1984).

18. T. M. Grist, A. J esmanowicz, J. B. Kneeland, W. Froncisz, and J . S. Hyde, Magn. Reson. Med. 6, 253 (1988).

19. J. T. Vaughan, H. P. Hetherington, J.G. Harrison, J . O. Otu, J. W. Pan, P.J. Noa, and G. M. Pohost, Phys. Med. (April/J une, 1993).

20. J. T. Vaughan, J. M. Vaughn, H. P. Hetherington, J. G. Harrison, P. J . Noa, and G. M. Pohost, Abstracts of the Society of Magnetic Resonance in Medicine, 12th Annual Meeting, New York, p. 1332, August 14-20, 1993.

21. J. S. Hyde, A. J esmanowicz, T. M. Grist, W. Froncisz, and J. B. Kneeland, Magn. Reson. Med. 4, 179 (1987).

22. D. I. Hoult, C.-N. Chen, and V. J . Sank, Magn. Reson. Med. 3, 339 (1984).

23. P. B. Roemer, W. A. Edelstein, C. E. Hayes, S. P. Souza, and O. M. Mueller, Magn. Reson. Med. 16, 192 (1990).

24. H. Merkle, M. Garwood, and K. Ugurbil, Abstracts of Society of Magnetic Resonance in Medicine, 12th Annual Meeting, New York, p. 1358, August 14-20, 1993.

25. J. S. Hyde, W. Song, J. Knight-Scott, and A. Jesmanowicz, Abstracts of Society of Magnetic Resonance in Medicine, 12th Annual Meeting, New York, p. 1340, August 14-20, 1993.

26. J. Murphy-Boesch and A. P. Koretzky, J. Magn. Reson. 54, 526 (1983).

27. A. Haase, J . Frahm, D. Matthaei, W. Haenicke, and K.-D. Merboldt, J. Magn. Reson. 67, 258 (1986).

28. R. Gruetter, Magn. Reson. Med. 29, 804 (1993).

29. A. J. Shaka, J. Keeler, and R. Freeman, J. Magn. Reson. 53, 313 (1983).

30. M. Garwood and Y. Ke, J. Magn. Reson. 94, 511 (1991).

31. R. Gruetter, G. Adriany, H. Merkle, and P. M. Andersen, Magn. Reson. Med. 36, 659 (1996).

32. R. Gruetter, M. Garwood, K. Ugurbil, and E. R. Seaquist, Magn. Reson. Med. 36, 1 (1996). 